\title{
ARTIKEL
}

\section{De gevaarlijke asielzoeker en het Unierecht}

\section{Gevaarzetting als grond voor uitsluiting van internationale bescherming}

Hans van Oort

\section{Inleiding}

De gevaarlijke asielzoeker slaagt er met gemak in om de aandacht van de publieke opinie te trekken. ${ }^{1}$ De in juni 2019 aangetreden staatssecretaris van Justitie en Veiligheid, Ankie Broekers-Knol, heeft aangegeven hard te zullen optreden tegen asielzoekers die overlast veroorzaken in en rond opvangcentra en daarbij bereid te zijn de 'randen van de wet op te zoeken'. ${ }^{2}$ Inmiddels is ook de zogenaamde Top $\mathrm{X}$-aanpak uitgerold, waarbij ketenpartners aan de hand van een lijst met overlastgevers intensief samenwerken om overlast terug te dringen. ${ }^{3}$

In deze bijdrage geef ik een uiteenzetting van de verblijfsrechtelijke consequenties die op basis van Europese wetgeving en rechtspraak kunnen worden verbonden aan het (vermeend) gevaarlijke gedrag van asielzoekers in Nederland. De beschrijving van het gevaarlijke gedrag van asielzoekers illustreer ik met de berichten die daarover in de diverse media zijn verschenen. De juridische kwalificatie van deze gevaarlijke asielzoekers levert een beknopt overzicht op van de huidige stand van zaken van EU-regelgeving en -rechtspraak over openbare orde, en van de knelpunten die daarbij horen in zowel het recht als de praktijk. Ik zal bijzondere aandacht besteden aan de ruimte die nationale autoriteiten hebben om vreemdelingrechtelijk op te treden tegen overlast gevende en gevaarlijke asielzoekers en in welke mate de rechten en belangen van de asielzoeker daarbij worden beschermd.

Binnen het bereik van mijn bijdrage valt zowel de vreemdeling die slechts kenbaar heeft gemaakt dat hij of zij internationale bescherming wenst en hangende de beoordeling van het verzoek nog in een opvangcentrum verblijft, als de vreemde-

1 Zie paragraaf 2 voor de verwijzingen naar mediaberichten ter onderbouwing van deze stelling.

2 R. Meijer en M. Sommer, 'Staatssecretaris Ankie Broekers-Knol over haar woeste portefeuille, asielzaken: "Ik wil de grenzen opzoeken", de Volkskrant 20 november 2019.

3 www.rijksoverheid.nl/actueel/nieuws/2020/02/03/aanpak-van-overlast-start-ook-in-noordenvan-het-land en zie Kamerstukken II 2019/20, 19637, nr. 2572, p. 3-4. 
ling die reeds erkend is als vluchteling of subsidiair beschermde. ${ }^{4}$ Het reguliere migratierecht blijft buiten beschouwing.

\section{De gevaarlijke asielzoeker}

Al naar gelang de ernst van het vertoonde gedrag onderscheid ik vier categorieën gevaarlijke asielzoekers. Ik beschrijf deze categorieën hier kort, geïllustreerd met verwijzingen naar berichten uit de media. In paragraaf 4 kom ik op deze indeling in categorieën terug bij het beantwoorden van de vraag of er verblijfsrechtelijke gevolgen verbonden kunnen worden aan de verschillende soorten gedragingen.

\subsection{Overlast veroorzakende vergrijpen}

Regelmatig in het nieuws is de asielzoeker die overlast veroorzaakt. ${ }^{5}$ Vaak vindt dat plaats in en rondom de opvangcentra. Zo ook in Budel. Volgens Henri de Wijkerslooth, voormalig waarnemend burgemeester van de gemeente Cranendonck, waar Budel toe behoort, doet de overlast die een deel van de asielzoekers veroorzaakt, nog het meest denken aan het gedrag van hangjongeren: 'denk aan meisjes nafluiten of een blikje bier jatten'. ${ }^{6}$ Te denken valt ook aan de bedreigingen en intimidaties op buslijn 73 tussen Emmen en Ter Apel. ${ }^{7}$ Onder overlast versta ik hier de vergrijpen die ook worden genoemd in de Rapportage Vreemdelingenketen 2018: (winkel)diefstal, zakkenrollerij, eenvoudige mishandeling, bedreiging, heling en vernieling. ${ }^{8}$

\subsection{Zwaardere strafrechtelijke vergrijpen}

Veel maatschappelijke onrust ontstond toen na het verschijnen van de Rapportage Vreemdelingenketen in mei 2019 bekend werd dat zwaardere misdrijven in deze rapportage niet waren gespecificeerd, maar ondergebracht onder het kopje

4 Een vluchteling is een onderdaan van een derde land die een gegronde vrees heeft voor vervolging (artikel 2(d) Kwalificatierichtlijn). Subsidiaire bescherming kan worden toegekend aan een onderdaan van een derde land of een staatloze die niet voor de vluchtelingenstatus in aanmerking komt, maar ten aanzien van wie er zwaarwegende gronden bestaan om aan te nemen dat hij in het land van herkomst of eerder verblijf een reëel risico loopt op ernstige schade (artikel 2(f) Kwalificatierichtlijn).

5 R. Rutten, 'Het is weer heibel in de bus naar Ter Apel', NRC 6 november 2018. C. Paauwe, 'Extra politie-inzet Ter Apel tegen overlast asielzoekers', NRC 11 juli 2019. J. Mansvelt en J. Krekels, 'Cranendonck is wanhoop nabij door overlast van asielzoekers', Eindhovens Dagblad 9 november 2019. J. Ariaans, 'Overloon vraagt om actie tegen foute vluchtelingen', De Gelderlander 4 mei 2019. P. Vissers, 'Personeel van "aso-azc's” doet elke twee weken aangifte van bedreiging of vernieling door asielzoekers', Trouw 19 april 2019. T. Borst, 'Kamer eist optreden tegen overlastplegers in asielzoekerscentra', de Volkskrant 27 februari 2019.

6 https://eenvandaag.avrotros.nl/item/cijfers-bevestigen-asielzoekers-uit-veilige-landen-gevenoverlast/.

7 NOS, 'Qbuzz eist maatregelen van COA tegen overlast in asielbus', 25 april 2019. RTV Noord, 'Pendelbus voor veiligelanders Ter Apel; lijn 73 slaat azc straks over'.

8 Ministerie van Justitie en Veiligheid, 'Rapportage Vreemdelingenketen periode januari-december 2018', p. 31. 
'overig'. ${ }^{9}$ Voor het eerst werd in deze rapportage een landelijk overzicht gemaakt van incidenten waarbij bewoners van asielzoekerscentra als verdachte zijn aangemerkt. Voorheen werd alleen gekeken naar incidenten op of rond de opvanglocaties zelf. De onrust leidde uiteindelijk tot het aftreden van de verantwoordelijke staatssecretaris Mark Harbers. Uit de lijst die de staatssecretaris alsnog naar de Tweede Kamer stuurde, blijkt dat het bij deze zwaardere vergrijpen ging om voornamelijk zware mishandeling en aanranding, en daarnaast om verkrachting, gijzeling en drie mogelijke gevallen van moord. ${ }^{10}$

\subsection{Terrorisme}

Regelmatig zijn er ook berichten over asielzoekers die in het land van herkomst hebben deelgenomen aan een terroristische organisatie en de asielprocedure gebruiken om Europa binnen te komen. ${ }^{11} \mathrm{Bij}$ de instanties die samen de vreemdelingenketen vormen, is bijzondere aandacht voor deze groep en er zijn meerdere onderzoeken geweest naar de signalering van terroristen onder de asielzoekers. ${ }^{12}$ De mogelijke dreiging van terrorisme heeft ertoe geleid dat de Inspectie Justitie en Veiligheid permanent toezicht houdt op het identificatie- en registratieproces van asielzoekers. ${ }^{13}$

\subsection{Artikel 1F Vluchtelingenverdrag}

Misdrijven tegen de vrede, oorlogsmisdrijven en misdrijven tegen de menselijkheid vormen in het Vluchtelingenverdrag een aparte uitsluitingsgrond. ${ }^{14}$ Gebaseerd op de spaarzame berichtgeving in de media, springt de asielzoeker die in deze categorie valt minder in het oog bij het grote publiek. ${ }^{15}$ Verhoogde aandacht voor deze groep was er vooral midden jaren negentig van de vorige eeuw toen honderden Afghaanse ex-medewerkers van de geheime dienst KhAD/WAD als asielzoeker in Nederland bleken te wonen. ${ }^{16}$

$9 \quad$ I. de Zwaan, 'Deze cijfers hebben Mark uiteindelijk de kop gekost', de Volkskrant 21 mei 2019.

10 Kamerstukken II 2018/19, 19637, nr. 33042 en www.tweedekamer.nl/kamerstukken/ brieven_regering/detail id=2019Z09820\&did=2019D20062.

11 S. Ephimenco, 'Het asielmonstrum lekt aan alle kanten en wordt misbruikt', Trouw 1 november 2018. R. Meijer, 'Screening asielzoekers nog altijd niet waterdicht', de Volkskrant 21 december 2016. J. Groen, 'Hooggeplaatste IS-terrorist onderweg naar Nederland of Duitsland', de Volkskrant 4 november 2015.

12 J. van Wijk en M.P. Bolhuis, 'Jihadisme en de vreemdelingenketen. De signalering van vermoedelijke jihadisten onder asielzoekers en jihadistische activiteiten in en rond asielzoekerscentra nader onderzocht'. Inspectie Veiligheid en Justitie, 'De opvolging van signalen uit het asielproces'.

13 Kamerstukken II 2015/16, 19637, nr. 2187.

14 Artikel 1F Vluchtelingenverdrag.

15 NOS, 'Verdachte commandant Syrische terreurgroep aangehouden in Kapelle', 24 mei 2019.

16 ACVZ, 'Artikel 1F Vluchtelingenverdrag in het Nederlands vreemdelingenbeleid', Den Haag: 2008, p. 19. 


\section{Gevaarzetting in het Europees asielrecht}

Het Unierechtelijk acquis voor asiel bestaat uit de Kwalificatierichtlijn (2011/95/ EU), de Procedurerichtlijn (2013/32/EU) en de Opvangrichtlijn (2013/33/EU). ${ }^{17}$ Verspreid in deze richtlijnen zijn normen te vinden die verblijfsrechtelijke consequenties verbinden aan overlast gevend of gevaarlijk gedrag van een asielzoeker. Van die normen volgt in deze paragraaf per richtlijn een uiteenzetting in hoofdlijnen. Waar dat van toepassing is, betrek ik ook de uitleg die inmiddels aan deze normen is gegeven door het Hof van Justitie (het Hof).

\subsection{Kwalificatierichtlijn: vluchtelingen}

De Kwalificatierichtlijn bepaalt wie voor internationale bescherming in aanmerking komt. Van alle bovengenoemde richtlijnen bevat de Kwalificatierichtlijn de meest complexe normen voor uitsluiting wegens gevaarzetting. De gevaarsnorm is namelijk anders voor vluchtelingen dan voor subsidiair beschermden. Ook maakt deze richtlijn onderscheid tussen een status en een verblijfstitel.

De vluchtelingenstatus kan volgens de Kwalificatierichtlijn om redenen van openbare orde worden geweigerd, ${ }^{18}$ niet worden verlengd of ingetrokken ${ }^{19}$ indien er goede redenen bestaan om de vreemdeling te beschouwen als een gevaar voor de veiligheid van de lidstaat waar hij zich bevindt of indien de vreemdeling een gevaar vormt voor de samenleving van die lidstaat, omdat hij definitief veroordeeld is voor een bijzonder ernstig misdrijf.

Uit artikel 21(2) Kwalificatierichtlijn volgt dat voor verwijdering van het grondgebied van de al dan niet formeel erkende vluchteling dezelfde criteria gelden, met als extra waarborg dat de lidstaten hierbij het beginsel van non-refoulement dienen te eerbiedigen. ${ }^{20}$

Ingevolge artikel 21(3) Kwalificatierichtlijn kan de verblijfstitel worden geweigerd, niet worden verlengd of worden ingetrokken wanneer er redenen bestaan om de uitzondering op het beginsel van non-refoulement als bedoeld in artikel 21(2) Kwalificatierichtlijn toe te passen. Het criterium luidt dan hetzelfde als hierboven genoemd voor weigeren, niet verlengen of intrekken van de vluchtelingenstatus. ${ }^{21}$ Een additionele grond voor het weigeren, niet verlengen of intrekken van de verblijfstitel kan worden gevonden in artikel 24(1) Kwalificatierichtlijn, waar wordt gesproken van 'dwingende redenen van nationale veiligheid of openbare orde'.

17 De Gezinsherenigingsrichtlijn (2003/86/EG), die van toepassing is op nareizende familie- en gezinsleden van asielzoekers, laat ik hier buiten beschouwing.

18 Artikel 14(5) Kwalificatierichtlijn.

19 Artikel 14(4) Kwalificatierichtlijn.

20 Artikel 21(1) Kwalificatierichtlijn.

21 HvJ EU 24 juni 2015, zaak C-373/13 (H.T.), JV 2015/258 m.nt. H. Battjes. 
Het weigeren, niet verlengen of intrekken van de vluchtelingenstatus van de zogenaamde $1 \mathrm{~F}^{\prime} \mathrm{er}^{22}$ vindt plaats wanneer er ernstige redenen zijn om aan te nemen dat de betreffende vreemdeling een misdrijf tegen de vrede, een oorlogsmisdrijf of een misdrijf tegen de menselijkheid heeft gepleegd. ${ }^{23}$ Ook de b- en cgrond van artikel $1 \mathrm{~F}$ Vluchtelingenverdrag zijn in de Kwalificatierichtlijn opgenomen. ${ }^{24}$

Bij de bepaling over de 1F'er valt direct op dat de Europese wetgever, anders dan bij de overige criteria, geen ruimte laat aan de nationale autoriteiten: zodra vaststaat dat er ernstige redenen zijn om aan te nemen dat de vreemdeling een in artikel 12(2)(a) omschreven misdrijf heeft gepleegd, dient de vluchtelingenstatus te worden geweigerd dan wel in voorkomend geval niet te worden verlengd of te worden ingetrokken. Voor de verwijdering van de 1F'er geldt slechts de bepaling dat lidstaten het beginsel van refoulement dienen te eerbiedingen, met inachtneming van hun internationale verplichtingen. ${ }^{25}$ Een verblijfstitel kan aan een 1 F'er worden geweigerd of niet verlengd vanwege 'dwingende redenen van nationale veiligheid of openbare orde'. ${ }^{26}$

\subsection{Kwalificatierichtlijn: subsidiair beschermden}

De subsidiaire beschermingsstatus kan worden geweigerd, ${ }^{27}$ worden ingetrokken of niet verlengd ${ }^{28}$ indien de vreemdeling een gevaar vormt voor de gemeenschap of de veiligheid van de lidstaat waar hij zich bevindt.

De verblijfstitel voor een subsidiair beschermde mag worden geweigerd, worden ingetrokken en hoeft niet te worden verlengd indien 'dwingende redenen van nationale veiligheid of openbare orde zich daartegen verzetten'. ${ }^{29}$

Bij verwijdering van het grondgebied van een subsidiair beschermde is enkel vereist dat de lidstaten het beginsel van non-refoulement eerbiedigen, met inachtneming van hun internationale verplichtingen. ${ }^{30}$

Verder kan, net als in geval van de (mogelijke) vluchteling, subsidiaire bescherming worden geweigerd en de reeds verleende status van subsidiaire bescherming worden ingetrokken of niet verlengd indien de vreemdeling een misdrijf tegen de vrede, een oorlogsmisdrijf of een misdrijf tegen de menselijkheid heeft gepleegd. ${ }^{31}$ Bij artikel 17(1)(b) valt op dat daar wordt gesproken over een 'ernstig misdrijf', terwijl bij uitsluiting van de vluchtelingenstatus in artikel 12(2)(b) Kwa-

22 Verwijzend naar artikel $1 \mathrm{~F}$ onder a Vluchtelingenverdrag.

23 Artikel 12(2)(a) en 14(3)(a) Kwalificatierichtlijn.

24 De b-grond ziet op ernstige, niet-politieke misdrijven en de c-grond gaat over handelingen die in strijd zijn met de preambule en artikel 1 en 2 van het VN Handvest.

25 Artikel 21(1) Kwalificatierichtlijn.

26 Artikel 24(1) Kwalificatierichtlijn.

27 Artikel 17(d) Kwalificatierichtlijn.

28 Artikel 19(3)(a) Kwalificatierichtlijn.

29 Artikel 24(2) Kwalificatierichtlijn.

30 Artikel 21(1) Kwalificatierichtlijn.

31 Artikel 17(1)(a) en 19(3)(a) Kwalificatierichtlijn. 
lificatierichtlijn wordt gesproken van een 'ernstig, niet-politiek misdrijf. Het Hof heeft geen duidelijke verklaring gegeven voor dit verschil: in het arrest Ahmed kwam het op dit punt niet verder dan dat er in het geval van de weigeringsgrond voor subsidiaire bescherming sprake moet zijn van 'meer algemeen een ernstig misdrijf. ${ }^{32}$

\subsection{Kwalificatierichtlijn: jurisprudentie}

Rest nog de vraag hoe de bovengenoemde criteria concreet dienen te worden uitgelegd. In het arrest H.T. heeft het Hof zich uitgesproken over de 'dwingende redenen van openbare orde en openbare veiligheid' die het criterium vormen voor weigering, niet verlenging of intrekking van de verblijfstitel van een asielstatushouder en een subsidiair beschermde. Het Hof sluit aan bij de eigen jurisprudentie over de uitleg van een grotendeels gelijkluidend criterium in de Burgerschapsrichtlijn (2004/38/EG) ${ }^{33}$ en overweegt dat er sprake moet zijn van een 'werkelijke, actuele en voldoende ernstige bedreiging, die een fundamenteel belang van de samenleving aantast' (het actuele-bedreigingscriterium). ${ }^{34}$ De uitleg van het openbareordebegrip dat geldt ten aanzien van Unieburgers is daarmee leidend geworden voor de toepassing van dat begrip op vluchtelingen en subsidiair beschermden. Het Hof erkent dat de Burgerschapsrichtlijn andere doelen nastreeft dan de Kwalificatierichtlijn. Tegelijkertijd mag volgens het Hof de omvang van de bescherming die een samenleving aan haar fundamentele belangen wenst te bieden, niet verschillen afhankelijk van de juridische status van de betrokken persoon. ${ }^{35}$ Verder maakt de Kwalificatierichtlijn onderscheid tussen erkenning of toekenning van de vluchtelingenstatus enerzijds en de verlening van de verblijfsvergunning anderzijds. De aanspraak op de rechten van hoofdstuk 7 van de richtlijn (toegang tot onderwijs, sociale zekerheid en dergelijke) zijn gekoppeld aan de toekenning van de vluchtelingenstatus en niet de verblijfsvergunning. Dat betekent, aldus het Hof, dat die aanspraken blijven bestaan als de verblijfsvergunning is ingetrokken op grond van openbare orde of nationale veiligheid. ${ }^{36}$ In het arrest $M, X$ en $X$ heeft het Hof inmiddels duidelijk gemaakt dat dit verschil tussen de vluchtelingenstatus en de verblijfsvergunning overeind blijft. ${ }^{37}$

Vast staat dat een enkele verwijzing naar een (strafrechtelijke) veroordeling onvoldoende is om een gevaar voor de openbare orde te motiveren. ${ }^{38}$ In het arrest $K$. en H.F. over de ongewenstverklaring van een Unieburger heeft het Hof nadere aanwijzingen gegeven voor de hantering van dit criterium. ${ }^{39}$ Per geval dient een beoordeling plaats te vinden op basis van het gedrag van de betrokken persoon. gebaseerd zijn op het gedrag van betrokkene. Strafrechtelijke veroordelingen vormen als zodanig geen reden voor deze maatregelen.'

39 HvJ EU 2 mei 2018, zaak C-331/16 en 366/16 (K. en H.F.), JV 2018/136 m.nt. M.A.K. Klaassen. 
Daarbij moet in het bijzonder rekening worden gehouden met de aard en ernst van de aan betrokkene verweten misdrijven of gedragingen, de mate waarin hij daarbij persoonlijk betrokken was, het eventuele bestaan van gronden voor uitsluiting van zijn strafrechtelijke aansprakelijkheid en het al dan niet bestaan van een strafrechtelijke veroordeling. Deze beoordeling is in het bijzonder van belang als de vreemdeling niet strafrechtelijk is veroordeeld voor de misdrijven of gedragingen waarvan hij wordt verdacht. Ook moet, en hier lijkt het Hof geïnspireerd te zijn door één van de Boultif-criteria van het EHRM, ${ }^{40}$ in aanmerking worden genomen hoeveel tijd sinds de vermoede misdrijven of handelingen is verstreken en hoe betrokkene zich nadien heeft gedragen. Daaruit moet blijken of het gedrag van de betrokkene nog steeds fundamentele waarden van de Unie aantast. Volgens het Hof impliceert artikel 27(2) Burgerschapsrichtlijn dat er een inschatting van het gedrag van de vreemdeling in de toekomst moet worden gemaakt, maar kan het enkele feit van het gedrag in het verleden aanleiding zijn tot de vaststelling dat aan de voorwaarden voor een ernstige bedreiging wordt voldaan. ${ }^{41}$ Het tijdsverloop sinds het vermeende plegen van het strafbare feit is een relevant gegeven in de beoordeling, maar de uitzonderlijke ernst van de betrokken handelingen kan aanleiding zijn om ook na een betrekkelijk lang tijdsverloop tot het oordeel te komen dat de ernstige bedreiging er nog steeds is. ${ }^{42}$

Ten aanzien van deelname aan de activiteiten van een terroristisch netwerk heeft het Hof in het arrest Lounani geoordeeld dat een asielaanvraag dan kan worden afgewezen op grond van artikel 12(2)(c) Kwalificatierichtlijn. ${ }^{43}$ De in dat artikel neergelegde grond voor uitsluiting is niet beperkt tot degenen die daadwerkelijk terroristische daden hebben gepleegd.

\subsection{Procedurerichtlijn}

Deze richtlijn stelt voorwaarden aan de procedures voor de toekenning en intrekking van de internationale bescherming. Het begrip 'openbare orde' kan onder meer een veroordeling wegens een ernstig misdrijf bestrijken, zo volgt uit preambule 24. Wanneer de openbare orde ernstig in het gedrang komt, moeten de lidstaten de behandelingsprocedure kunnen versnellen. ${ }^{44}$

\subsection{Opvangrichtlijn}

De Opvangrichtlijn verschaft normen voor de opvang van verzoekers op internationale bescherming. De toegang tot de bewaringsaccommodatie mag alleen worden beperkt indien dit volgens het nationale recht objectief noodzakelijk is voor o.a. de veiligheid en de openbare orde. ${ }^{45}$ In het arrest J.N. oordeelde het Hof

43 HvJ EU 31 januari 2017, zaak C-573/14 (Lounani), JV 2017/78 m.nt. M. van Eik en AB 2017/203 m.nt. P.R. Rodrigues.

44 Artikel 31(8) Procedurerichtlijn.

45 Artikel 10(4) Opvangrichtlijn. 
dat bewaring van asielzoekers op grond van artikel 8(3)(e) Opvangrichtlijn alleen is toegestaan wanneer 'zijn persoonlijke gedrag een werkelijke, actuele en voldoende ernstige bedreiging vormt die een fundamenteel belang van de samenleving aantast'. ${ }^{46}$ Daarmee sluit het Hof voor de uitleg van het openbareordebegrip in de Opvangrichtlijn dus aan bij zijn eerdere uitleg van het openbareordebegrip in andere richtlijnen. ${ }^{47}$ In het geval van J.N. had de staatssecretaris ter motivering van het gevaar voor de openbare orde verwezen naar de vele antecedenten van de vreemdeling (waaronder 21 veroordelingen voor vermogensdelicten). Volgens de Afdeling was daarmee onvoldoende kenbaar gemotiveerd waarom het gedrag van J.N. een actueel en voldoende ernstig gevaar voor de openbare orde vormde. ${ }^{48}$ Dit bevestigt dat het Unierecht een hoge drempel stelt aan het inroepen van de openbare orde ter beperking van een individueel recht. ${ }^{49}$

Op grond van het arrest Haqbin kan worden gesteld dat overlast gevende asielzoekers niet uit de opvang mogen worden gezet, ook niet tijdelijk. Voorziening in de meest elementaire behoeften zoals wonen, eten, zich kleden en wassen moet volgens het Hof gewaarborgd zijn. ${ }^{50}$ Wel mogen in reactie op ernstige inbreuken op de regels of bij ernstige vormen van geweld, de voorzieningen worden beperkt, bijvoorbeeld in de vorm van het intrekken of beperken van de dagvergoeding. ${ }^{51}$ Ook mag bij wijze van sanctie worden bepaald dat een asielzoeker in een afzonderlijk gedeelte van het opvangcentrum moet verblijven, waar hij geen contact mag hebben met bepaalde bewoners van het centrum, of dat hij wordt overgeplaatst naar een ander centrum of andere vorm van huisvesting. ${ }^{52}$

\section{Verblijfsrechtelijke consequenties voor gevaarlijke asielzoekers}

In deze paragraaf komen de twee voorgaande paragrafen samen en beantwoord ik de vraag of er verblijfsrechtelijke gevolgen verbonden kunnen worden aan gedrag van asielzoekers zoals beschreven in paragraaf 2 .

\subsection{Overlast in en rond asielzoekerscentra}

De overlast gevende asielzoeker vormt onder het Unierecht wellicht wel een werkelijke en actuele bedreiging, maar zal in de regel geen voldoende ernstige bedreiging zijn voor een fundamenteel belang van de samenleving. Weigering tot verlening of de intrekking van het verblijfsrecht komt daarmee niet snel in zicht. De Europese Commissie wijst er in het verband van de veelplegers op dat onder bepaalde omstandigheden veelvuldig gepleegde lichte feiten een bedreiging voor

47 J.N., para 64-67.

48 ABRvS 8 april 2016, JV 2016/143 m.nt. M.F. Wijngaarden.

49 ABRvS 8 april 2016. J.N., punt 10 van noot Cornelisse.

50 HvJ EU 12 november 2019, zaak C-233/18 (Haqbin), JV 2019/197 m.nt. C.H. Slingenberg, para 46-48.

51 Haqbin, para 51.

52 Haqbin, para 52. 
de openbare orde kunnen vormen. ${ }^{53}$ Het aantal strafbare feiten is daarbij echter slechts een van de factoren; er moet ook rekening worden gehouden met de aard van de strafbare feiten en de veroorzaakte schade.

Een meer voor de hand liggende aanpak van deze groep is de beperking van hun rechten onder de Opvangrichtlijn. Uit het arrest Haqbin is inmiddels duidelijk geworden dat het intrekken of beperken van de dagvergoeding en overplaatsing naar een andere afdeling of een ander centrum volgens het Hof geen afbreuk doet aan de waardigheid van de asielzoeker en daarmee is toegestaan. Uit de Top Xaanpak blijkt dat de Nederlandse autoriteiten stevig inzetten op een aanpak van de overlast gevende asielzoeker via beperking van rechten onder de Opvangrichtlijn. ${ }^{54}$ De inmiddels tot het verleden behorende Nederlandse praktijk van overplaatsing van overlast gevende asielzoekers naar een Extra Begeleidingsen Toezichtlocatie kon ook na Haqbin door de Unierechtelijke beugel. ${ }^{55}$ Sinds februari 2020 is een nieuwe separate opvanglocatie voor overlast gevende asielzoekers in gebruik: de Handhaving en Toezichtlocatie (HTL) in Hoogeveen. ${ }^{56}$ Voor alle bewoners van de HTL geldt een strikte gebiedsbeperking.

\subsection{Zwaardere strafrechtelijke vergrijpen}

Meer dan bij het veroorzaken van overlast in en om asielzoekerscentra, staat bij de asielzoeker die zwaardere strafrechtelijke vergrijpen begaat de vraag centraal of hij een voldoende ernstige bedreiging voor de openbare orde vormt. Daarbij wordt de vraag relevant of de betreffende asielzoeker een vluchteling of een subsidiair beschermde is en of het gaat om weigering, niet verlenging of intrekking van de status of de verblijfstitel.

Bij het weigeren, niet verlengen of intrekken van de verblijfstitel van een vluchteling of subsidiair beschermde, zal moeten worden voldaan aan het actuele-bedreigingscriterium. Zoals in de vorige paragraaf beschreven, is dat criterium door het Hof inmiddels vrij ver uitgewerkt. Bij het weigeren, niet verlengen of intrekken van de status is er een verschil tussen het criterium voor de vluchteling en voor de subsidiair beschermde. Voor eerstgenoemde vermeldt de Kwalificatierichtlijn dat er goede redenen moeten bestaan om hem te beschouwen als een gevaar voor de veiligheid of dat hij definitief veroordeeld moet zijn voor een bijzonder ernstig

53 Mededeling van de Europese Commissie aan het Europees Parlement en de Raad betreffende de richtsnoeren voor een betere omzetting en toepassing van richtlijn 2004/38/EG betreffende het recht van vrij verkeer en verblijf op het grondgebied van de lidstaten voor de burgers van de Unie en hun familieleden, $\operatorname{COM(2009)} 313$ def., p. 13. Naar analogie hier van toepassing, omdat in de jurisprudentie van het Hof de uitleg van het openbareordebegrip dat geldt ten aanzien van Unieburgers leidend is geworden voor de toepassing van dat begrip op vluchtelingen en subsidiair beschermden. Zie ook: A. Pahladsingh, 'De complexiteit van openbare orde', A\&MR 2018, 6-7, p. 326-327.

54 Kamerstukken II 2019/20, 19637, nr. 2572, p. 3-4.

55 C.H. Slingenberg, 'Hof van Justitie: overlast gevende asielzoekers mogen niet uit opvang worden gezet, ook niet tijdelijk', Verblijfblog 15 november 2019.

56 Kamerstukken II 2019/20, 19637, nr. 2572, p. 5-6. Voor de evaluatie van de ebtl, zie: WODC, 'Asielzoekers in het gareel? Plan-, proces en effectevaluatie werking extra begeleiding en toezichtlocaties', 2019. 
misdrijf. ${ }^{57}$ Voor de subsidiair beschermde geldt dat hij een gevaar moet vormen voor de gemeenschap of de veiligheid van de lidstaat. ${ }^{58}$ Uit de rechtspraak van het Hof is vooralsnog niet duidelijk geworden hoe het verschil tussen deze criteria moet worden uitgelegd en hoe dit verschil in criteria gerechtvaardigd kan worden.

\subsection{Terrorisme}

Van de vluchteling of subsidiair beschermde die daadwerkelijk in Nederland een terroristische daad begaat, zal de verblijfstitel kunnen worden geweigerd, niet verlengd of ingetrokken op grond van het actuele-bedreigingscriterium. Wanneer de daad van terrorisme buiten het land van toevlucht is begaan, zal weigering, intrekking of niet verlenging van de vluchtelingenstatus kunnen plaatsvinden op grond van artikel 12 lid 2 sub c Kwalificatierichtlijn, waarbij uit het arrest Lounani inmiddels is gebleken dat deze uitsluitingsgrond ook opgaat voor deelname aan de activiteiten van een terroristisch netwerk.

\subsection{Artikel 1F Vluchtelingenverdrag}

De gronden uit artikel 1F Vluchtelingenverdrag zijn overgenomen in de Kwalificatierichtlijn, met dien verstande dat bij de subsidiaire beschermingsstatus in artikel 17(1)(b) Kwalificatierichtlijn wordt gesproken over 'ernstig misdrijf' in plaats van 'ernstig, niet-politiek misdrijf' zoals in het Vluchtelingenverdrag en bij de vluchtelingenstatus van artikel 12(2)(b) Kwalificatierichtlijn. Uit het arrest $K$. en H.F. is duidelijk geworden dat ook in het geval van een $1 F^{\prime}$ er voldaan moet worden aan het criterium van een werkelijke, actuele en voldoende ernstige bedreiging.

\section{Knelpunten}

Tot besluit een kort overzicht van enkele probleemgebieden die in zowel rechtspraak als praktijk ontwaard kunnen worden wanneer gevaarlijk gedrag als uitgangspunt wordt genomen voor het weigeren, intrekken of niet verlengen van verblijfsrecht van asielzoekers.

De koppeling tussen gevaarzetting en verblijfsrecht die in dit artikel centraal staat, is een schoolvoorbeeld van de inhoudelijke versmelting van strafrecht en migratierecht. ${ }^{59}$ Daarmee is het fenomeen crimmigratie stevig ingebed in het Europees asielrecht. Volgens Stumpf zorgt een dergelijke inbedding ervoor dat crimmigratie een drijvende kracht wordt achter het politieke debat en versterkt het de roep om steeds strenger beleid. ${ }^{60}$ Ook in het Nederlandse debat over asiel zijn daarvan tekenen zichtbaar. Zo wijst Stronks in zijn Verblijfscolumn mijns inziens terecht op de grote gevoeligheid die bij publiek en politiek waarneembaar

57 Artikel 14(4) en 21(1) Kwalificatierichtlijn.

58 Artikel 17(1)(d) en 19(3)(a) Kwalificatierichtlijn.

59 J. Stumpf, 'The Crimmigration Crisis: Immigrants, Crime, and Sovereign Power', American University Law Review 2006, 56, p. 376.

60 'In gesprek met professor Juliet Stumpf', Crimmigratie \& Recht 2019, 3 (2), p. 100. 
is voor discrepanties tussen theorie en praktijk in het migratierecht, terwijl voor andere rechtsgebieden veeleer lijkt te worden geaccepteerd dat de uitvoering van beleid nooit volmaakt kan zijn. ${ }^{61}$ Tekenend is ook de redenering van de staatssecretaris in haar brief van 18 december 2019 over de aanpak van overlast gevende asielzoekers. Daarin staat dat de aanpak van overlast gevende asielzoekers de hoogste prioriteit heeft, omdat het gedrag van criminele asielzoekers 'funest is voor het draagvlak voor asielopvang'. ${ }^{62}$ Daarmee lijkt het ook op beleidsniveau normaal te zijn geworden om de acceptie van de ene asielzoeker afhankelijk te stellen van het overlast gevende gedrag van een andere asielzoeker.

Zoekend naar een rode lijn in de Europese regelgeving die van toepassing is op de gevaarlijke asielzoeker, kan in ieder geval worden gesteld dat er op de staatssecretaris in alle gevallen een aanzienlijke onderzoeks- en motiveringsplicht rust waarbij alle feitelijke en juridische omstandigheden van het geval worden meegenomen. ${ }^{63}$ Dit werpt een flinke drempel op voor uitsluiten van internationale bescherming. Het is dan ook niet verrassend dat uit het in 2019 verschenen onderzoeksrapport van de Commissie De Leeuw is gebleken dat het geheel van rechtsregels en jurisprudentie waar de IND rekening mee dient te houden ertoe leidt dat weinig asielvergunningen daadwerkelijk worden ingetrokken. ${ }^{64}$

Bijzondere aandacht verdient de kwetsbare rechtspositie van 1F'ers. Al in 2008 werd door de Adviescommissie voor Vreemdelingenzaken (ACVZ) uitgebreid onderzoek gedaan naar de praktische gevolgen van het spanningsveld tussen de toepassing van artikel $1 \mathrm{~F}$ Vluchtelingenverdrag en artikel 3 EVRM. ${ }^{65}$ Dit spanningsveld leidt er concreet toe dat 1F'ers in een juridisch niemandsland terechtkomen, omdat zij vanwege hun verleden niet in aanmerking komen voor een verblijfsstatus, maar tegelijkertijd wegens het absolute verbod van refoulement niet uitgezet kunnen worden. ${ }^{66}$ Ondanks herhaalde oproepen daartoe, is in Nederland nog niet voorzien in een menswaardige oplossing voor deze situatie, bijvoorbeeld in de vorm van een aparte verblijfsstatus. ${ }^{67}$

61 M.C. Stronks, 'Migratierecht zònder illegalen is irreëel en dus onhaalbaar', NRC 20 januari 2020.

62 Kamerstukken II 2019/20, 19 637, nr. 2572, p. 1.

63 Zie hierover nader: J.K.A.M. Waasdorp, 'Algemene onderzoeks- en motiveringsplicht voor staatssecretaris bij communautaire openbareordebegrippen', A\&MR 2016, 8, p. 390-392.

64 Commissie De Leeuw, 'Onderzoek vermoeden van misstand bij de IND', 20 mei 2019.

65 ACVZ, 'Artikel 1F Vluchtelingenverdrag in het Nederlands vreemdelingenbeleid', Den Haag: 2008.

66 J. van Wijk en M.P. Bolhuis, 'Asielzoekers als (vermeende) daders', Tijdschrift voor Veiligheid 2017, 16 (2/3), p. 11-25. M.P. Bolhuis, H. Battjes en J. van Wijk, 'Undesirable but Unreturnable Migrants in the Netherlands', Refugee Survey Quarterly 2017, 36, p. 61-84.

67 M.P. Bolhuis, 'Gedoog de 1F'ers die niet terug kunnen', Trouw 24 februari 2015. M.P. Bolhuis en J. van Wijk, 'De Arabische Lente en artikel 1F Vluchtelingenverdrag', Justitiële verkenningen 2015, 41 (3), p. 90-100. Z. Yakut-Bahtiyar, Exclusion clauses of the Refugee Convention in relation to national immigration legislations, European policy and human rights instruments: Article $1 F$ versus the non-refoulement principle (diss. Tilburg), Oisterwijk: Wolf Legal Publishers 2016, zie met name p. 260-266. 


\section{Conclusie}

Het Unierecht laat ruimte voor een maatwerkaanpak van diverse vormen van overlast gevend en gevaarlijk gedrag door asielzoekers. Als het gaat om beperking van de voorzieningen die aan de asielzoeker worden verstrekt, heeft het Hof inmiddels duidelijk gemaakt dat voorziening in de meest elementaire behoeften gewaarborgd moet blijven. Bij weigering, intrekking of niet verlenging van het verblijfsrecht geldt in de meeste gevallen dat moet worden voldaan aan het criterium van de werkelijke, actuele en voldoende ernstige bedreiging voor een fundamenteel belang van de samenleving. De drempel die daarmee is gevormd, zal in de meeste gevallen te hoog zijn om overlast gevende asielzoekers het verblijfsrecht te ontzeggen of te ontnemen. Bij zwaardere strafrechtelijke vergrijpen kan in theorie wel aan de toets worden voldaan, maar lijkt het geheel aan complexe regelgeving er in de praktijk toe te leiden dat relatief weinig vergunningen vanwege de openbare orde worden geweigerd of ingetrokken. Indien wel kan worden geweigerd of ingetrokken, kan het absolute verbod op refoulement van artikel 3 EVRM nog in de weg staan aan uitzetting. Het ziet er daarom naar uit dat het in de praktijk voor de staat niet makkelijk is om gevaarlijke asielzoekers het verblijfsrecht te ontzeggen of te ontnemen. Gezien het zwaarwichtige belang aan de zijde van de asielzoeker die bescherming vraagt tegen vervolging of ernstige schade, is dat mijns inziens een goede zaak. 